\title{
Effects of Cobalt(II)Sulfate Addition on Structure and Corrosio $n$ Resistance of Alloy Micro-arc oxidation Coating on the ZL108 Aluminum
}

\author{
Jie Hu ${ }^{l}$, Ping Wang ${ }^{1}$ 2, 3, *, DanDan Liao ${ }^{1}$, XiYue Sun ${ }^{l}$, ZeYu Gong ${ }^{1}$, JiWei Liu ${ }^{1}$, Dan Xiong ${ }^{1}$, \\ Dong Xiang ${ }^{1}$, XiaoTao $\mathrm{Zu}^{2}$, XiaoWei Wei ${ }^{3}$ \\ ${ }^{1}$ School of New Energy and Materials, Southwest Petroleum University, Chengdu, 610500, China \\ ${ }^{2}$ School of Physics, University of Electronic Science and Technology of China, Chengdu, 611731, \\ China \\ ${ }^{3}$ The Postdoctoral Station at Xihua University Based on Collaboration Innovation Center of Sichuan \\ Automotive Key Parts, School of Materials Science and Engineering, Xihua University, Chengdu, \\ 610039, China \\ *E-mail: 818wp@163.com
}

doi: $10.20964 / 2020.06 .78$

Received: 25 February 2020 / Accepted: 8 April 2020 / Published: 10 May 2020

Micro-arc oxidation (MAO) coatings were formed on ZL108 aluminum alloy in silicate electrolyte with $\mathrm{CoSO}_{4}$. Scanning electron microscopy (SEM), X-ray diffraction (XRD), X-ray photoelectron spectroscopy (XPS) and electrochemical workstation were used to investigate the effects of $\mathrm{CoSO}_{4}$ on the microstructure, phase composition, elemental distribution and corrosion resistance of the MAO coatings. The results showed that the addition of $\mathrm{CoSO}_{4} \quad$ increased the micro arc oxidation voltage, which increased the coating formation rate, resulting in an increase in the thickness of the MAO coatings. After the addition of $\mathrm{CoSO}_{4}$, the discharge on the coating surface was more uniform, which made the coating flatter. The phases of the MAO coatings were mainly composed of $\alpha-\mathrm{Al}_{2} \mathrm{O}_{3}, \gamma-\mathrm{Al}_{2} \mathrm{O}_{3}$ and $\mathrm{SiO}_{2}$. The XPS test results showed that $\mathrm{CoSO}_{4}$ was converted to $\mathrm{CoO}$ and $\mathrm{Co}_{3} \mathrm{O}_{4}$, which made the MAO coatings denser. Electrochemical corrosion tests showed that the corrosion resistance of the coatings with $\mathrm{CoSO}_{4}$ was improved. Therefore, the addition of $\mathrm{CoSO}_{4}$ can optimize the structure of the MAO coating and improve its comprehensive properties.

Keywords: ZL 108 aluminum alloy; Micro-arc oxidation; Cobalt(II)Sulfate; Corrosion resistance

\section{$\underline{\text { FULL TEXT }}$}

(C) 2020 The Authors. Published by ESG (www.electrochemsci.org). This article is an open access article distributed under the terms and conditions of the Creative Commons Attribution license (http://creativecommons.org/licenses/by/4.0/). 